\title{
Job Satisfaction and Pay for Performance (P4P)
}

\author{
Sonika Chaudhary ${ }^{1}$, Cheshta kashyap ${ }^{2}$ \\ ${ }^{1,2}$ (Department of Management Studies, Maharishi Markandeshwar University, Sadopur - Ambala, India)
}

\begin{abstract}
The ultimate purpose behind the P4P concept is to establish a direct relation between an employee's job performance and the payment he/she will be receiving for that. As we all know that "As you sow so shall you reap" is the main crux for the pay for performance. Many organizations also give the extra perks and facilities for the extra work done like extra vacation etc. In today's scenario the cost of incentive we are paying and the higher performance results they are giving are in the same side but if we go on the downside, this is also an big issue that in many organizations people are not satisfied by the pay for performance or the incentive they are receiving or the increased monetary reward they are received yet because it is not up to mark according to them. In this empirical research we gather the data to analyze the impact of pay for performance on the Job Satisfaction and the target leads the whole population of private employee serving at the private bank and is declared to be a closed sample including 200 researchers. Further scope of the study reveals the other demographic factors which affect the pay for performance.
\end{abstract}

Keywords: incentive, performance, monetary reward.

\section{INTRODUCTION}

Incentives are those plans which are predetermined ethics and things which are standardized, as well as policies are well understood to distribute the funds and to determine the funds also. Robert J. Greene, opined "Pay can be in the form of short-term (one year or less) or long-term (two years or more) incentives/bonuses and employee ownership programs". "Bonuses" are incentives or extra payment given for the judgment and the required performances which are allocated at the period end and need justification to give to the employees.(1) "There is an important difference in the use of the terms merit pay and pay for performance by the government and the private sector that should be noted". In the view of government, the pay for performance and merit pay are synonyms to each other. But in the upcoming scenario it is treated as the same in these years especially in the private sector. The pay for performance is closely directly related to make the business up to new heights and to optimize the competitive business as well. The analysts of the various private sector opined that the annual pay and annual compensation is exclusively dependent on the wholly solely success of the organization rather on the performance of the individual. (4)To make the pay more effective the system for the performance compensation associated that with this system we can face more and more challenges and the tenure system based compensation plans will never be quick as well as easy. By taking this in to consideration, this type of researchers helps out to the supportive agencies to consider the pay for the performance. To put more emphasized, they discuss how agencies can design, implement, and operate a pay for performance compensation strategy. To give the successful for any organization they need to make an intended investment of effort, money and time. To fulfill the above requirements, enterprises make more and more investments to be made to extend far beyond the requirement of the bonuses and increase in the pay itself. The most important part to identify the introduction regarding the pay for performance system can also identify the weaknesses in different areas such as relation with the employee, employee satisfaction and employees' communications must be addressed. Thus, it is evident that Pay for Performance is a vital tool to enhance overall productivity of human resources and needs investigation to develop meaningful strategies.

\section{REVIEW OF LiterATURE}

Tor Eriksson et al. (2009) (2) investigated that the impacts of various schemes of pay and the performance policies and the feedback employee effort. They chose twice pay schemes a tournament and a piece rate. They defined this as a negative effect of peer because the performance feedback minimizes the of the low 
performer's work quality. Their study provided the new evidence on the impact of feedback on the relative performance on effort by using particular task. Salim Chahine et al. (2014) examined in their research titled "Top management ties with board members: How they affect Pay-performance sensitivity and IPO performance" This research was the first study on the effects of pay performance sensitivity on the IPOs in the presence of social ties and family ties of the top managers with board members. They found that both social ties and family ties increase pay performance sensitivity as well as it also improves the performance of initial public offerings rather it reduces the negative effect of family ties. Alexander Hu ttenbrink et al. (2014) propounded in their eminent research title "Pay-for-performance - Does one size fit all? A multi-country study of Europe and the United States" they investigated that how formal country-level institutions affect pay-for-performance directly and if institutions have a moderating effect on the relation between ownership structure and pay-for- performance contracts. They conducted an empirical analysis based on 2766 firm-year observations for the years 2005-2008. Their empirical results showed that whereas strong shareholder protection substitutes pay-for-performance, disclosure requirements complement pay-for-performance. Overall, results provided evidence for the relevance of formal institutions as determinants of executive compensation contracts. George D. Cashmanin Studied "Pay-performance sensitivity and firm size: Insights from the mutual fund industry" researcher examined that ex ante decision to make an agent's payperformance sensitivity an inverse function of organization size. This research focused on mutual funds and their decision to use compensation contracts that reduce the advisor's marginal compensation as the fund grows (a declining-rate contract) over the dominant contract type, where marginal compensation is unrelated to fund size (a single-rate contract). Amzaleg et al. examined "CEO control, corporate performance and pay-performance sensitivity" They developed a model that suggested that reverse causality should also be considered. The model predicted that when good performance is expected, a powerful CEO will push for a contract with higher PPS. They took Data from 135 Israeli companies over a five-year period for the model's main prediction. They did empirical analysis showed that when the CEO is the chairman of the board of directors and thus is more powerful in affecting his compensation scheme, he achieves a high PPS in good periods (in terms of corporate performance), compared to similar powerful CEOs in periods of bad performance, and also compared to less powerful CEOs in good periods. Anna Dodo Nova et al. investigated that Compensation and performance: An experimental study stated that how compensation structure affects performance in a simple but effort-consuming task. This was an experimental study, the subjects were asked to multiply two-digit numbers for $40 \mathrm{~min}$ and were paid using either a linear (with different pay for performance sensitivities) or a convex (option based) compensation mechanism. They investigated that perunit wage has a non-linear positive effect on performance: whereas increasing per-unit compensation from $\$ 0$ to $\$ 0.02$ or from $\$ 0.05$ to $\$ 0.15$ has virtually no effect on performance, an increase from $\$ 0.02$ to $\$ 0.05$ results in higher productivity. They found that option-based compensation results in better performance. Sudipta Basu et al. evaluated "Corporate governance, top executive compensation and firm performance in Japan" they evaluated that for 174 large Japanese corporations during 1992-1996, we find that top executive pay is higher in firms with weaker corporate governance mechanisms, controlling for standard economic determinants of pay. They found that the excess pay related to ownership and monitoring variables is negatively associated with subsequent accounting performance, consistent with the presence of an agency problem. They do not, however, find an association between this excess pay and subsequent stock returns. (8)Helena et al. analyzed in their research titled Do compensation plans with performance targets provides better incentives?. To evaluate the effectiveness of these plans at attracting and providing incentives to executives, they created compensation plans with fixed firm cost and executive valuation and calculate their expected total lifetime incentives. They inculcate the performance vesting targets provide the least cost effective incentives, performance exercise targets provide the largest risk incentives, option plans are generally superior to restricted stock plans, and calendar vesting is only efficient up to a maximum of three years. Performance exercise targets can increase the expected total lifetime incentives provided by compensation plans.(4) Alex Bryson et al. analyzed in their research titled Do salaries improve worker performance the effects of salaries on worker performance by exploiting a natural experiment in which some workers in a particular occupation (football referees) switch from short-term contracts to salaried contracts. Worker performance improves among 
those who move onto salaried contracts relative to those who do not. The finding is robust to the introduction of worker fixed effects indicating that it is not driven by better workers being awarded salary contracts. Nor is it sensitive to workers sorting into or out of the profession Josse et al. propounded in their research titled Dynamic incentive effects of relative performance pay: A field experiment had conducted a field experiment among 189 stores of a retail chain to study dynamic incentive effects of relative performance pay. Employees in the randomly selected treatment stores could win a bonus by outperforming three comparable stores from the control group over the course of four weeks. As predicted by theory, they found that treatment stores that lag far behind do not respond to the incentives, while the responsiveness of treatment stores close to winning a bonus increases in relative performance. On average, the introduction of the relative performance pay scheme does not lead to higher performance. (12)Akinobu Shuto et al. Executive compensation and earnings management: Empirical evidence from Japan. They investigated that the relation between discretionary accounting choices and executive compensation in Japanese firms. The results showed that the use of discretionary accruals increases executive compensation. The analyses also shown that firm managers receiving no bonus adopt income-decreasing accruals and extraordinary items. In particular, evidence shows that negative extraordinary items are strongly associated with no bonus payment.(12)Chong M. Laua et al analyzed in their research titled How do they affect job satisfaction, they opined that interest on the optimum use of measures which are nonfinancial (e.g. in the Balanced Scorecard) particularly assumes that these measures are essential to overcome the inadequacies of financial measures. However, it remains unclear (1) if the behavioral effects of these nonfinancial measures are different from those of financial measures; and (2) whether these effects are influenced by the relative importance of nonfinancial measures vis-à-vis financial measures. This study hypothesizes that the use of performance measures for evaluation of the performance will significantly affect job satisfaction of the managers.

\section{OBJECTIVE OF THE STUdy}

This study examines to find out the impact of pay for performance on the job satisfaction. As this is empirical research, we had done analysis and evaluation on the overall effectiveness of pay for performance.

\section{RESEARCH METHODOLOGY}

Population and Sample: The main research conducted in the area of Delhi/NCR of the total employees targeted in the private sector bank. The sample denotes the total population of private employee employed at the private bank and it is declared to be a target area inculcating 200 researchers. By taking the base of the sampling we can make the data of different public and private banks and employees were randomly selected from these banks and take the utmost consideration of the direct and indirect impact of pay for performance.

\section{RESPONSE RATE}

Total 180 questionnaires were distributed to the concerned respondents but only 172 questionnaires in totality filled by different respondents and get back from different banks, after screening only 120 responses were further used for analysis and respondents gave the feedback was $75 \%$ within a 30days.

\section{Methods Of The Data Collection}

Whole work which leads to the performance we did through the questionnaire as a main tool. Questionnaire included two parts: previous part directly leads to psychographic information inclusive of 5 different factors which include various factors like age and gender etc. \& and the other factor is linked with the job tenure as well as correlated to questions regarding the satisfaction of the job which create the impact on the promotion and pay as well.

\section{ANALysis PaRT}

The distribution of the frequency which is accumulated by all the personal information from the different variables we gather like demographic variables. The different personal information which we gather bifurcate in two 
parts which include the gender related to 78 males and also females 42 from total of 120 responses, which represent the percentage of male for $60 \%$ and female for $40 \%$ as well. The collected information segregated and valued that the responses for various age group received was 42\% from the 21-30 age group of people and rest of the $8 \%$ responses were made by the 51-50 age group of people. The married respondent's ratio was calculated at $46 \%$ and single respondents were $44 \%$ in total. This is also exaggerated that the more feedbacks fetch from other that the banking sector that is $31 \%$ and only with the difference of just $1 \%$ percent came from the banking sector department. When the research divided in the different job tenures of different people of various classes the respondents leads to $28 \%$ fallen under the level of 3-5 years of job tenure and near about the $18.5 \%$ of the feedbacks came from the job tenure of less than the one year as well as to the 5-10 year also.

Q1. Are you clearly understood the human resource policies?

- Agree

- Disagree

\begin{tabular}{|l|l|l|}
\hline Sr.No. & Statement & \%age \\
\hline 1. & Agree & 86 \\
\hline 2. & Disagree & 14 \\
\hline
\end{tabular}

Interpretation: $86 \%$ people are agreeing for the clearly understood of the human resource policies rather $14 \%$ are disagree for the same.

Q2. Are Extra perks and benefits deployed to the employees creating positive impact on job satisfaction?

\begin{tabular}{|l|l|l|}
\hline Sr.No. & Statement & \%age \\
\hline 1. & Yes & 98 \\
\hline 2. & No & 02 \\
\hline
\end{tabular}

Interpretation: 98\% of the total respondents are seems to be positive for the Extra perks and benefits deployed to the employees creating positive impact on job satisfaction and $2 \%$ respondents are not agree with this statement.

Q3. Enthusiasm of the employees has increased as a result of pay for performance. Are you agree with this statement?

\begin{tabular}{|l|l|l|}
\hline Sr.No. & Statement & \%age \\
\hline 1. & Yes & 82 \\
\hline 2. & No & 18 \\
\hline
\end{tabular}

Interpretation: $82 \%$ of the respondents are in favour that Enthusiasm of the employees has increased as a result of pay for performance rather $18 \%$ are not in favour as they considered that the other factors also affect for the performance.

Q4. What do you suggest that we should focus on future skills requirements? 
IOSR Journal of Business and Management (IOSR-JBM)

\begin{tabular}{|l|l|l|}
\hline Sr.No. & Statement & \%age \\
\hline 1. & Agree & 98 \\
\hline 2. & Disagree & 02 \\
\hline
\end{tabular}

Interpretation: Majority of the respondents are agree for that we should focus on future skills requirements but $2 \%$ are not agree with the same.

Q5. Are Employers committed to continue training and development for their employees?

\begin{tabular}{|l|l|l|}
\hline Sr.No. & Statement & \%age \\
\hline 1. & Yes & 78 \\
\hline 2. & No & 12 \\
\hline
\end{tabular}

Interpretation: $78 \%$ of the respondents are agree that Employers committed to continue training and development for their employees and $12 \%$ respondents are disagree with the same.

Q6. Cooperation and coordination accelerates as an impact of pay for performance. Give your comments?

Q7. Is group Incentives creates positive impact on the job satisfaction?

\begin{tabular}{|l|l|l|}
\hline Sr.No. & Statement & \%age \\
\hline 1. & Agree & 72 \\
\hline 2. & Disagree & 28 \\
\hline
\end{tabular}

Interpretation: Majority of the respondents are in favour of the statement that group Incentives creates positive impact on the job satisfaction but $28 \%$ of them are disagree with the same.

Q8. Honesty and integrity increases as a result of pay for performance. Give your indispensable opinion?

\section{Findings}

Statistical finding is carried to analyze the relation with the variables like independent variable that is pay for performance and the other one dependent variable that is job satisfaction. The result inculcate the overall relation between the two variable like independent and dependent variables which is there to elaborate the value of the dependent variable which ultimately analyzed by using the independent variables values. Influencing factors which creates the impact of the variables which are independent like pay and promotion which are exaggerated in the theoretical scenario of the research and which is further utilize for the impact of dependent variables which are the influencing factor like age, gender etc 


\section{Discussion}

The findings highlighted the variable which is independent variable that is Pay and dependent variable of the employees from the private sector which influence the impact on the job satisfaction. It showed in the factors that is job tenure, other facilities also affect the level of satisfaction of the Job. The result research evaluated the affect on the performance on the satisfaction level of the job at different private sector banks of Delhi/NCR. Results propounded that direct incentive has created positive impact on the job satisfaction. As the employee who perform well in the bank got the reward and remuneration better than the peer group and ultimately have urged more to the progress and upliftment of the current profile to move further for promotion The result examined the impact on the pay for performance created direct and positive impact on the job satisfaction at different private sector banks of Delhi/NCR. The study is limited to the specific region. The scope inculcated which comprising more private sector banks of different states. One persuading factor like pay for performance deprived in the effect of satisfaction level of job was used, in future more persuading factors of job satisfaction can be analyzed job tenure, other facilities, supervision etc.

\section{REFERENCES}

[1] H. Y. Chiang and F. Ohtake, "Performance-pay and the gender wage gap in Japan", 34, 2014, 71-88.

[2] T. Eriksson, A. Poulsen and M. C. Villeval, "Feedback and Incentives Experimental Evidence", Labour economics, 16, 2009, 679-688.

[3] S. Chahine and M. Goergen, "Top management ties with board members: How they affect Pay-performance sensitivity and IPO performance", Journal of Corporate Finance, 27, 2014, 99-115.

[4] H. Brinka, J. Oehmichen, M. S. Rapp and M. Wolff, "Pay-for-performance - Does one size fit all? A multi-country study of Europe and the United States", International Business Review, 2014.

[5] L. Bulan, P. Sanyal and Z. Yan, "A few bad apples: An analysis of CEO performance pay and firm productivity", 62, 2010, 273-306.

[6] Amzalega, O. H. Azarb, U. B. Zionb and A. Rosenfeld, "CEO control, corporate performance and pay-performance sensitivity", Journal of economic Behavior \& Organization, 106, 2014, 166-174.

[7] S. Cohen and B. Lauterbach, "Differences in pay between owner and non-owner CEOs: Evidence from Israel School of Business Administration, Bar Ilan University, 2007.

[8] H. Pinto and M. Widdicks, "Do compensation plans with performance targets provide better incentives", Department of Finance, The University of Illinois at Urbana-Champaign, USA, 2014.

[9] A. Bryson, B. Buraimo and R. Simmons, "Do salaries improve worker performance", A National Institute of Economic and Social Research and Centre for Economic Performance, LSE, United Kingdom ,University of Central Lancashire, United Kingdom Lancaster University Management School, United Kingdom, 2010.

[10] J. Delfgaauw, R. Dur, A. Non and W. Verbeke, “ Dynamic incentive effects of relative performance pay: A field experiment”, Erasmus University Rotterdam, The Netherlands Tinbergen Institute, the Netherlands, Germany, IZA, Germany Maastricht University, the Netherlands, 2014.

[11] A. Shuto, "Executive compensation and earnings management: Empirical evidence from Japan", Higashimita, Tamaku, Kawasaki 2148580, 2007, Japan.

[12] M. L. Chong, M. Sholihinb, "How do they affect job satisfaction”, Department of Accounting and Finance (M250), UWA Business School, The University of Western Australia, 2005. 